\title{
The role of serum apelin in retinopathy of prematurity
}

\author{
This article was published in the following Dove Press journal: \\ Clinical Ophthalmology \\ 21 February 2017 \\ Number of times this article has been viewed
}

\author{
Yasser F Ali' \\ Salah El-Morshedy' \\ Abdulbasit Abdulhalim \\ Imam $^{2}$ \\ Nasser Ismai \\ A Abdelrahman' \\ Riad M Elsayed ${ }^{3}$ \\ Usama M Alkholy' \\ Nermin Abdalmonem \\ Mohammed M Shehab' \\ 'Department of Pediatrics, Faculty of \\ Medicine, Zagazig University, Zagazig, \\ ${ }^{2}$ Department of Pediatrics, Al-Azhar \\ Faculty of Medicine-Girls, Cairo, \\ ${ }^{3}$ Pediatric Neurology Unit, Pediatric \\ Department, Mansoura University, \\ Mansoura, Egypt
}

Objective: To evaluate the role of serum apelin as a diagnostic tool in retinopathy of prematurity (ROP) disease.

Patients and methods: Thirty-eight preterm infants (60\% male) with gestational age ranging from 30 to 36 weeks admitted to the neonatal intensive care unit, KJO Hospital, Saudi Arabia with proven diagnosis of ROP were included in the study. In addition, 27 preterm infants without ROP served as controls. All newborn infants in the study were subjected to adequate history taking, full clinical examination, and fundus examination by indirect ophthalmoscope (at 4-6 weeks) as well as determination of serum apelin at birth and at 4-6 weeks of age.

Results: The study revealed that oxygen therapy longer than 7 days' duration, cesarean section (as a mode of delivery), sepsis, mechanical ventilation, blood transfusion, premature rupture of membranes, pneumothorax, perinatal asphyxia, cardiac problems, and neonatal jaundice were considered as risk factors related to development of ROP. Serum apelin levels were significantly lower in patients than controls $(P<0.001)$ at time of diagnosis of the disease (4-6 weeks) while no significant differences were observed in levels at birth.

Conclusion: Serum apelin was found to be of significant diagnostic value in the occurrence of ROP.

Keywords: retinopathy of prematurity, preterm infants, serum apelin

\section{Introduction}

Major improvements in neonatal survival have been observed in the last ten years, particularly at low gestational age. ${ }^{1}$ Retinopathy of prematurity (ROP) is a proliferative disorder of immature retinal vasculature with multifactorial etiology. ${ }^{2} \mathrm{ROP}$ develops in $16 \%$ of all premature births, the figure rising to around $60 \%$ of infants weighing $<1,500 \mathrm{~g}$ at birth and $65 \%$ for infants $<1,250 \mathrm{~g}$. Some studies suggest that as smaller and younger babies are surviving, its incidence is increasing. However, better understanding of screening and management of these babies have resulted in a decrease in its incidence. ${ }^{3}$ Both oxygen-regulated and non-oxygen-regulated factors contribute to normal vascular development and retinal neovascularization. Vascular endothelial growth factor (VEGF) is an important oxygen-regulated factor, while non-oxygen-regulated growth factor is insulin-like growth factor-I (IGF-I). ${ }^{4}$ The initial phase of retinal vessel growth retardation occurs from birth to postmenstrual age of 30-32 weeks. Oxygen plays a critical role in this process. Hypoxia and hyperoxia, by the high levels of supplemental oxygen the infant may receive in the neonatal intensive care unit (NICU), inhibit production of growth factors, such as VEGF, which causes cessation of normal retinal growth, and vessels constriction with a potential for vaso-obliteration of new immature vessels, resulting in tissue hypoxia that releases
Correspondence: Riad M Elsayed Pediatric Neurology Unit, Pediatric Department, Faculty of Medicine, Mansoura University, PO 35516, El Gomhoria Street, Mansoura City, 35516 Mansoura, Egypt

$\mathrm{Tel}+20502243117$

Fax +20 502262024

Email shewaka1971@yahoo.com 
factors to stimulate new retinal blood vessel growth, a process called neovascularization (Phase II). ${ }^{5}$

Apelin is a pro-inflammatory adipocyte-derived factor that participates in vascular wall inflammation. It was identified in 1998 as an endogenous ligand of the human orphan G protein-coupled receptor, APJ. ${ }^{6}$ Apelin receptor is expressed in several cell types. ${ }^{7}$ The angiogenic activity is the consequence of apelin action on the proliferation and migration of the endothelial cells. Apelin expression is upregulated during new vessels formation and downregulated following vessels stabilization. ${ }^{8}$

The aim of this study is to evaluate the role of serum apelin in ROP.

\section{Patients and methods}

This is a prospective observational case-control study. It included 82 infants with a gestational age $<32$ weeks and a birth weight of $\leq 1,500 \mathrm{~g}$. The infants were screened for ROP at NICU, KJO Hospital, Saudi Arabia, during January 2014-March 2016.

Thirty-eight (20 males and 18 females) with classified ROP completed our study group. Twelve preterm babies who died before first ophthalmological examination and five preterm babies with multiple congenital anomalies were excluded from this study. Twenty-seven preterm neonates who did not develop ROP (16 males and 11 females) were studied as control group.

Ethical approval was obtained from the institutional review board of KJO Hospital, Saudi Arabia, and a written informed consent was provided by parents of all children prior to the study.

All the studied groups were subjected to detailed history taking, including identification, cause of admission, neonatal history, maternal history, and family history. Full clinical examinations include:

1. Assessment - gestational age was assessed using the date of the mother's last menstrual period and modified Ballard Score. ${ }^{9}$

2. Ophthalmological examination - fundus examination was performed after pharmacological mydriasis starting 2 hours before the examination with cyclophrine eyedrops (combination of $2.5 \%$ phenylephrine and $1 \%$ cyclopentolate), applied three times at 30-minute intervals. Under topical anesthesia with boxinate eyedrops, an infantile eyelid speculum was applied. Using indirect binocular ophthalmoscope (Keeler Vantage ${ }^{\circledR}$, Tampa, FL, USA), 20-diopter double aspheric Volk lens, the entire retina was carefully examined in all directions of gaze and with gentle pressure on the eyeball, using a scleral indenter for better visualization of the peripheral retina. The first examination was performed between 4 and 6 weeks of age or between 31 and 33 weeks of postmenstrual age. Follow-up examinations were made every week until the retinal vascularization was well into zone III. The presence or absence of the ROP plus disease, the zone, stage, and the extent of the ROP were recorded according to the international classification of ROP (stages 1-5). ${ }^{10}$

\section{Laboratory tests}

1. Routine laboratory investigations: Complete blood count, blood culture, C-reactive protein, liver and kidney functions, serum electrolytes, and arterial blood gases were monitored.

2. Measurement of serum apelin peptide: Blood samples were obtained from studied 82 preterm babies twice: at birth (cord blood) and after 4-6 weeks. Two-milliliter venous blood sample was collected on ethylenediaminetetraacetic acid, centrifuged for 10 minutes at $5,000 \mathrm{rpm}$, and the plasma was separated. The serum was stored at $-80^{\circ} \mathrm{C}$ in polypropylene tubes until the time of assay. Serum level of apelin peptide was measured using enzyme-linked immunosorbent assay kits (RayBiotech, Inc, Norcross, GA, USA. EIA Kit). ${ }^{11}$

\section{Statistical analysis}

Quantitative data were expressed as mean \pm standard deviation (X土 SD). Qualitative data were expressed as frequency and percentage (\%). Receiver operating characteristic (ROC) curve was used to define the best of serum apelin cutoff value.

Data were analyzed using Statistical Package for the Social Sciences (SPSS) version 18.0 (SPSS Inc., Chicago, IL, USA). A $P$-value $<0.05$ was considered significant.

\section{Results}

The demographic characteristics of the 38 ROP and 27 nonROP infants were analyzed. The patient group included 38 neonates of gestational age ranging from 30 to 36 weeks (X \pm SD: $34.37 \pm 1.29$ weeks) and mean birth weight of $2.42 \pm 0.54 \mathrm{~kg}$, compared with 27 age- and sex-matched preterm infants without ROP as control group (Table 1).

Our study showed a highly significant negative correlation between stages of severity of ROP and Apgar score at 5 minutes of life in the patient group, while no correlation was found as regards mode of delivery, premature rupture of membranes, mechanical ventilation, pneumothorax, sepsis, blood transfusion, neonatal jaundice, and perinatal asphyxia. 
Table I Demographic characteristics of studied groups

\begin{tabular}{|c|c|c|c|c|}
\hline Variables & $\begin{array}{l}\text { ROP group } \\
(n=38)\end{array}$ & $\begin{array}{l}\text { Non-ROP } \\
(n=27)\end{array}$ & $\begin{array}{l}\text { Test of } \\
\text { significance }\end{array}$ & $P$-value \\
\hline \multicolumn{4}{|c|}{ Gender, n (\%) } & 1.000 \\
\hline Female & $18(47.4)$ & II (40.8) & $\chi^{2}=0.000$ & \\
\hline Male & $20(52.6)$ & $16(59.2)$ & & \\
\hline \multicolumn{4}{|c|}{ Gestational age (weeks) } & 0.467 \\
\hline$X \pm S D$ & $30.37 \pm 1.29$ & $31.14 \pm 1.33$ & $t=0.534$ & \\
\hline Range & $28-32$ & $28-32$ & & \\
\hline \multicolumn{4}{|c|}{ Birth weight $(\mathrm{kg})$} & 0.197 \\
\hline$X \pm S D$ & $1.42 \pm 0.54$ & $1.58 \pm 0.48$ & $t=1.696$ & \\
\hline Range & $987-1,205$ & $1,015-1,227$ & & \\
\hline
\end{tabular}

Notes: $t=$ Student's $t$-test, $\chi^{2}=$ chi-square test, $P>0.05$ : nonsignificant. Abbreviations: $X \pm S D$, mean \pm standard deviation; $R O P$, retinopathy of prematurity.

While, a significant positive correlation between the stages of ROP and oxygen therapy for $>7$ days was observed $(P<0.05)$ (Table 2).

A comparison of mean levels of serum apelin between the groups of patients and controls was undertaken. At the sampling time at birth, there were no significant differences between respective mean values in the two groups $(P>0.05)$. Measurements made at 4-6 weeks after birth showed higher mean concentrations of serum apelin in patients $(P<0.05)$ (Table 3$)$.

Serum apelin level cutoff value in samples taken at birth was $2.18 \mathrm{ng} / \mathrm{mL}$, with sensitivity of $42.9 \%$, specificity of $80 \%$, positive predictive value of $68.2 \%$, negative predictive value of $58.3 \%$, and diagnostic accuracy of $59.1 \%$ (Figures 1 and 2). While the cutoff value of serum apelin levels taken at 4-6 weeks age was $2.7 \mathrm{ng} / \mathrm{mL}$, with sensitivity of $62.9 \%$, specificity of $80 \%$, positive predictive value of $75.9 \%$, negative predictive value of $68.3 \%$, and diagnostic accuracy of $71 \%$ (Figures 3 and 4 ).

\section{Discussion}

ROP is a disorder of the developing retina of low-birthweight preterm infants that potentially leads to blindness in a small but significant percentage of those infants. In almost all term infants, the retina and retinal vasculature are fully

Table 2 Correlation between ROP and some risk factors among patients group

\begin{tabular}{|c|c|c|c|c|c|}
\hline \multirow[t]{2}{*}{ Variables } & \multicolumn{3}{|c|}{ Stages of ROP $(n=38)$} & \multirow[t]{2}{*}{$\chi^{2}$} & \multirow[t]{2}{*}{$P$-value } \\
\hline & I $(n=4)$ & II $(n=8)$ & III-V (n=26) & & \\
\hline Apgar score (at $5 \mathrm{~min}$ ) & & & & & $<0.00 \mathrm{I}(\mathrm{HS})$ \\
\hline $4-6(n=3)$ & $0(0.0 \%)$ & $0(0.0 \%)$ & $3(100 \%)$ & 25.430 & \\
\hline $7-10(n=32)$ & $23(71.9 \%)$ & $8(25 \%)$ & I (3.1\%) & & \\
\hline Mode of delivery & & & & & 0.144 (NS) \\
\hline CS $(n=25)$ & $14(56 \%)$ & $7(28 \%)$ & $4(16 \%)$ & 3.869 & \\
\hline Vaginal $(n=10)$ & $9(90 \%)$ & $\mathrm{I}(10 \%)$ & $0(0.0 \%)$ & & \\
\hline PROM & & & & & 0.102 (NS) \\
\hline Negative $(n=28)$ & $16(57 \%)$ & $8(29 \%)$ & $4(14 \%)$ & 4.565 & \\
\hline Positive $(n=7)$ & 7 (100\%) & $0(0.0 \%)$ & $0(0.0 \%)$ & & \\
\hline $\mathrm{O}_{2}$ therapy & & & & & $0.039(\mathrm{~S})$ \\
\hline$<7$ days $(n=3)$ & $3(100 \%)$ & $0(0.0 \%)$ & $0(0.0 \%)$ & 5.902 & \\
\hline$>7$ days $(\mathrm{n}=32)$ & $20(62.5 \%)$ & $8(25 \%)$ & $4(12.5 \%)$ & & \\
\hline MV & & & & & $0.425(\mathrm{NS})$ \\
\hline Negative $(n=20)$ & $16(80 \%)$ & $4(20 \%)$ & $0(0.0 \%)$ & & \\
\hline Positive $(n=15)$ & $7(47 \%)$ & $4(26.5 \%)$ & $4(26.5 \%)$ & 1.712 & \\
\hline Pneumothorax & & & & & 0.374 (NS) \\
\hline Negative $(n=26)$ & 17 (65\%) & $7(27 \%)$ & $2(8 \%)$ & 1.968 & \\
\hline Positive $(n=9)$ & $6(67 \%)$ & I (II\%) & $2(22 \%)$ & & 0.252 (NS) \\
\hline \multicolumn{6}{|l|}{ Sepsis } \\
\hline Negative $(n=13)$ & $10(77 \%)$ & $3(23 \%)$ & $0(0.0 \%)$ & 2.759 & \\
\hline Positive $(n=22)$ & $13(59 \%)$ & $5(23 \%)$ & $4(18 \%)$ & & \\
\hline Blood transfusion & & & & & 0.977 (NS) \\
\hline Negative $(n=27)$ & $18(67 \%)$ & $6(22 \%)$ & 3 (II\%) & & \\
\hline Positive $(n=8)$ & $5(62.5 \%)$ & $2(25 \%)$ & I (I2.5\%) & 0.048 & \\
\hline Neonatal jaundice & & & & & 0.558 (NS) \\
\hline Negative $(n=28)$ & $18(64 \%)$ & $6(21 \%)$ & $4(15 \%)$ & 1.168 & \\
\hline Positive $(n=7)$ & $5(7 \mid \%)$ & $2(29 \%)$ & $0(0.0 \%)$ & & \\
\hline Perinatal asphyxia & & & & & 0.192 (NS) \\
\hline Negative $(n=34)$ & 23 & 8 & 3 & 4.978 & \\
\hline Positive $(n=I)$ & 0 & 0 & I & & \\
\hline
\end{tabular}

Notes: $\chi^{2}=$ chi-square test, $P<0.05$ : significant, $P>0.05$ : nonsignificant, $P<0.00$ I: highly significant.

Abbreviations: ROP, retinopathy of prematurity; CS, c-section; PROM, premature rupture of membranes; MV, mechanical ventilation; S, significant; NS, nonsignificant; HS, highly significant; min, minutes. 
Table 3 Serum apelin levels at birth and 4-6 weeks among the studied groups

\begin{tabular}{|c|c|c|c|c|}
\hline $\begin{array}{l}\text { Serum } \\
\text { apelin levels }\end{array}$ & $\begin{array}{l}\text { ROP } \\
\text { group }\end{array}$ & $\begin{array}{l}\text { Non-ROP } \\
\text { group }\end{array}$ & $t$ & $P$-value \\
\hline \multicolumn{4}{|c|}{ Serum apelin at birth $(\mathrm{ng} / \mathrm{mL})$} & 0.313 \\
\hline Range & I.4-2.4 & $2-2.6$ & 1.032 & \\
\hline$X \pm S D$ & $1.5 \pm 0.6$ & $1.8 \pm 0.4$ & & \\
\hline \multicolumn{4}{|c|}{ Apelin at 4-6 weeks $(\mathrm{ng} / \mathrm{mL})$} & $0.024 *$ \\
\hline Range & $1.6-2.7$ & $2.5-3.9$ & 5.312 & \\
\hline$X \pm S D$ & $1.7 \pm 0.8$ & $2.9 \pm 0.4$ & & \\
\hline
\end{tabular}

Notes: $* P<0.05$ : significant difference $t=$ Student's $t$-test. A comparison of mean levels of serum apelin between the groups of patients and controls was undertaken. At the sampling time at birth, there were no significant differences between respective mean values in the two groups $(P>0.05)$. Measurements made at 4-6 weeks after birth showed higher mean concentrations of serum apelin in patients $(P<0.05)$.

Abbreviations: ROP, retinopathy of prematurity; $X \pm S D$, mean \pm standard deviation.

developed, and ROP cannot occur; however, in preterm infants, the development of the retina, which proceeds from the optic nerve head anteriorly during the course of gestation, is incomplete, with the extent of the immaturity of the retina depending mainly on the degree of prematurity at birth. ${ }^{12}$ The rate of ROP in most premature infants has gone down greatly in developed countries over the past few decades due to better care in the NICU. However, more babies born very early are now able to survive, and these very premature infants are at the highest risk for ROP. ${ }^{13}$ Studies have shown that apelin was involved in vascular pathophysiology ${ }^{6}$ and act as an angiogenic factor stimulating retinal endothelial cells' proliferation, migration, and vascular tube formation. ${ }^{14,15}$

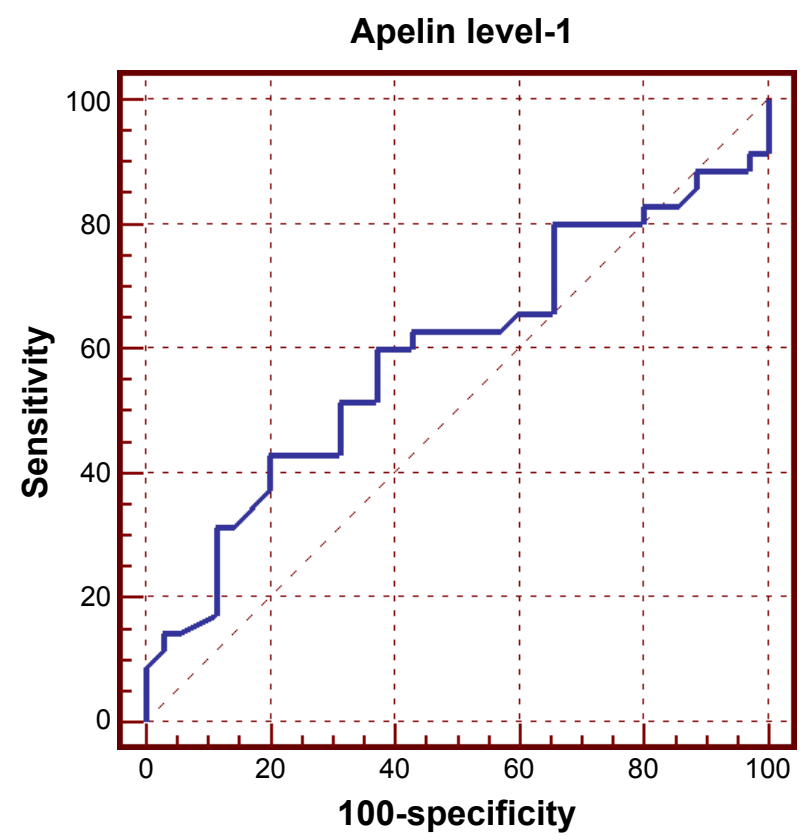

Figure I ROC curve between patients and control groups as regards serum apelin levels at birth.

Abbreviation: ROC, receiver operating characteristic.

\section{Apelin level-1}

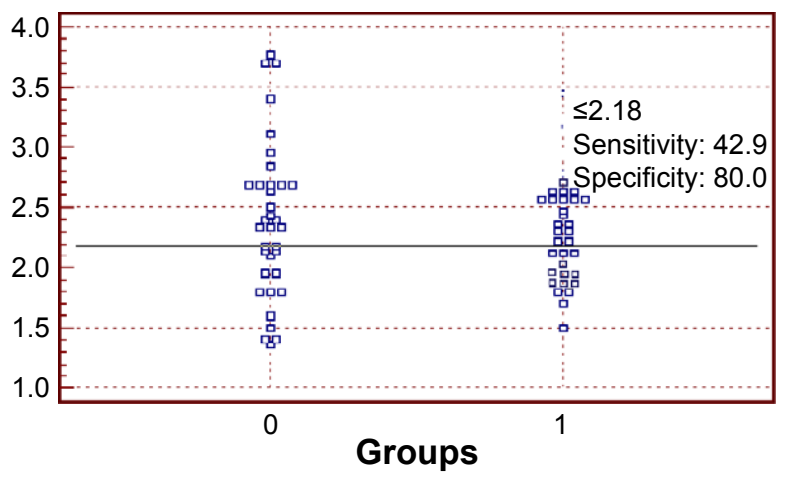

Figure 2 Interactive dot diagram between patients and control groups as regards serum apelin levels at birth.

Notes: The best cutoff value was $2.18 \mathrm{ng} / \mathrm{mL}$, with a sensitivity of $42.9 \%$ and a specificity of $80 \%$ I $\mathrm{I}=$ patients; $0=$ control.

In the current study, 65 infants born with a gestational age before 32 weeks were screened for development of ROP, 38 infants developed ROP (58\%), while only $41.5 \%$ were free. ROP reported by Taquin et al ${ }^{16}$ study (32.4\%) involved only low-birth-weight infants, while Chen et al ${ }^{17}(10.8 \%)$ study involved infants with higher gestational age and birth weight (up to $2 \mathrm{~kg}$ and or 34 weeks' gestational age).

In the present study, we investigate the most significant risk factors related to the development of ROP; we found that the most important risk factors included $\mathrm{O}_{2}$ therapy $>7$ days, cesarean section (as a mode of delivery), sepsis, prolonged mechanical ventilation, blood transfusion, premature rupture of membranes (PROM), development of hypoxia due to

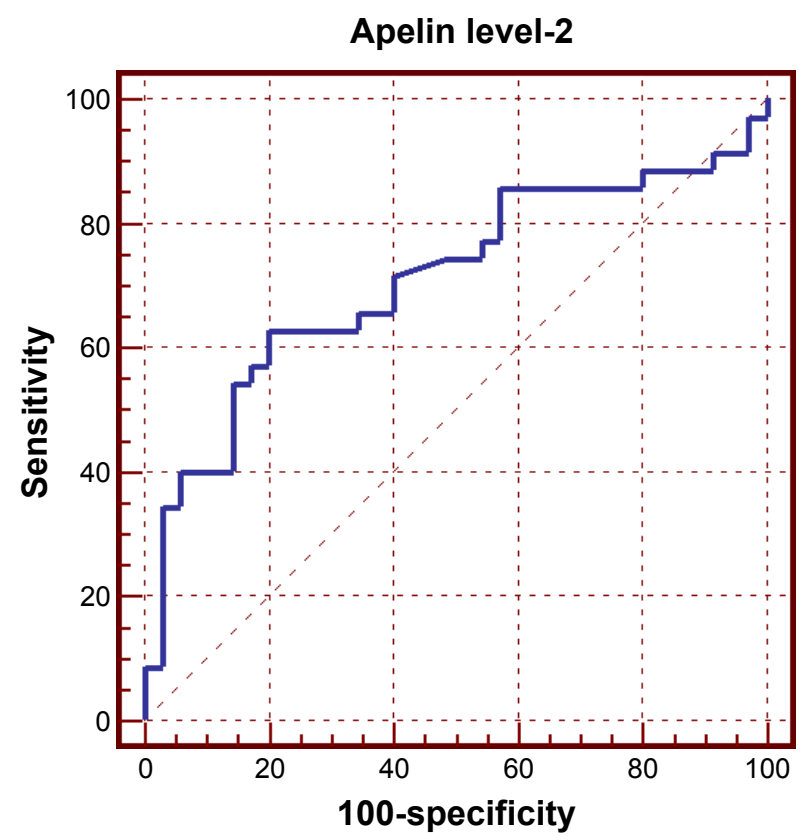

Figure 3 ROC curve between patients and control groups as regards serum apelin levels, at 4-6 weeks of age.

Abbreviation: ROC, receiver operating characteristic. 


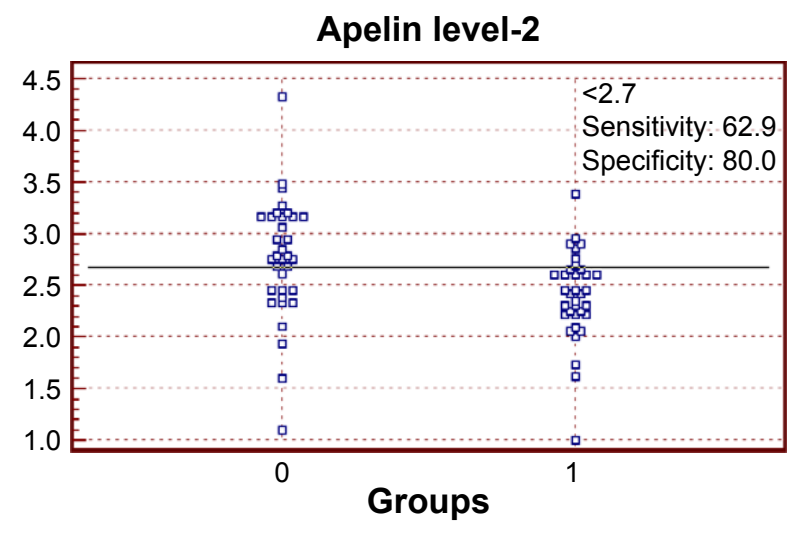

Figure $\mathbf{4}$ Interactive dot diagram between patients and control groups as regards serum apelin at 4-6 weeks of age.

Notes: The best cutoff value was $2.7 \mathrm{ng} / \mathrm{mL}$, with a sensitivity of $62.9 \%$ and a specificity of $80 \%$. I= ROP; $0=$ non-ROP.

Abbreviation: ROP, retinopathy of prematurity.

pneumothorax, hypoxic ischemic encephalopathy, cardiac problems, and newborn jaundice. These findings were going with many other studies as Chen et al, ${ }^{18}$ while in Hadi and Hamdy ${ }^{19}$ cohort study, the risk factors for ROP were sepsis, continuous positive airway pressure, mechanical ventilation, neonatal indirect hyperbilirubinemia, intra ventricular hemorrhage, patent ductus arteriosis, and red blood cell and/ or plasma transfusion. All these factors were significantly related to the occurrence of ROP and development of severe form of the disease except for indirect hyperbilirubinemia.

In our study, Apgar score in the first minute of life was mainly 4-6 (91.4\%) (moderate Apgar score) and at 5 minutes was mainly $>6$ (7-9) (high Apgar score); there was a high significant negative correlation between severity of ROP and Apgar score at 1 and 5 minutes of life in the patients group. This comes in agreement with Martínez-Cruz et al' ${ }^{20}{ }^{20}$ study.

In our study, serum apelin was detectable in all the studied groups, which come in concordance with the study of Malamitsi-Puchner et al, ${ }^{21}$ who found that apelin was detectable in the serum of all studied neonates. We also evaluate the serum apelin level-1 (at birth) and level-2 (after 4-6 weeks) in both patients and control groups.

The average serum apelin level- 1 is nearly equal in both patients and control groups; this comes in disagreement with Cekmez et al' ${ }^{22}$ study where the non-ROP (control) group had higher serum apelin level-1 than ROP (patients) group.

After 4-6 weeks, apelin level-2 was higher in non-ROP group than the ROP group, and this comes in agreement with Cekmez et al's ${ }^{22}$ study.

ROC curve was used to define the best cutoff value of apelin level-1 in our patients, which was 2.18 , with sensitivity of $42.9 \%$, specificity of $80 \%$, positive predictive value of $68.2 \%$, negative predictive value of $58.3 \%$, and diagnostic accuracy of $59.1 \%$. Another (ROC) curve was used to define the best cutoff value of apelin level-2 which was 2.7, with sensitivity of $62.9 \%$, specificity of $80 \%$, positive predictive value of $75.9 \%$, negative predictive value of $68.3 \%$, and diagnostic accuracy of $71 \%{ }^{23}$

High positive predictive value of serum apelin level-2 test in our study prove that apelin test can predict the ROP early and prevent loss of vision if not controlled early enough. Sensitivity might be attributed to small number of the studied patients group (sensitivity of $62.9 \%$ and specificity of $80 \%$ ), yet it suggests that the role of serum apelin in ROP should be further investigated.

Geiger et $\mathrm{al}^{24}$ investigated the role of hypoxia on the expression of the adipokine apelin. Hypoxia in adipose tissue leads to a dysregulation of the expression of adipokines. He improved that apelin expression and secretion by human adipocytes are strongly induced under hypoxic conditions and that the early response on hypoxia with apelin induction is dependent on hypoxia-inducible factor $1-\alpha(\mathrm{HIF}-1 \alpha)$. Eyries et $\mathrm{al}^{25}$ also reported that apelin is a hypoxia-inducible gene by both in vitro and in vivo studies. They found that hypoxia-induced apelin expression was mediated by HIF through a hypoxia-response element located within the first intron of the gene. Moreover, they determined that hypoxic induction of apelin expression regulated endothelial proliferation. Concerning the relationship between apelin and VEGF, they reported that apelin could enhance endothelial cell proliferation and aggregation in the presence of VEGF. ${ }^{26,27}$

Lim et al's ${ }^{28}$ study reported that human preterm and term labor significantly decreased apelin gene expression, but had no effect on APJ expression. They suggested an important role for apelin and APJ in the regulation of placental flow and vasculogenesis. The result of Zhang et $\mathrm{al}^{29}$ showed that both apelin and APJ were positively expressed in the fibrovascular membrane of the ROP. The results also showed that apelin stimulates migration, proliferation, and capillary-like tube formation of RF/6A cells but not human umbilical venous endothelial cells and that apelin promotes angiogenesis in vivo. Therefore, they conclude that apelin/APJ signals seem to serve as a stimulatory factor in angiogenesis, probably in retina. Cekmez et $\mathrm{al}^{22}$ used other tests (with serum apelin level test) to detect serum IGF-1 to aid early detection of ROP - it improved that circulating apelin concentrations in preterm babies may be linked with ROP like IGF-1 levels - while Lofqvist et $\mathrm{al}^{30}$ used postnatal weight gain and serum IGF-1 for early detection of ROP.

\section{Conclusion}

Serum apelin was found to be of significant diagnostic value in the occurrence of ROP. Serum apelin values were 
significantly lower in patients group compared with controls group as regards ROP. There is also a significant positive correlation between the use of oxygen therapy $>7$ days and the severity of the ROP. The best cutoff value of serum apelin to detect ROP (after 4-6 weeks) was $(2.7 \mathrm{ng} / \mathrm{mL}$ ) with a sensitivity of $62.9 \%$ and specificity of $80 \%$. Further studies are needed to 1) declare if serum apelin levels get affected by other diseases, such as respiratory distress syndrome, hemorrhagic diseases, or surgical conditions, and in neonates 2) consolidate the value of serum apelin in management of neonates admitted to NICU with ROP as a predictive marker.

\section{Disclosure}

The authors report no conflicts of interest in this work.

\section{References}

1. Effer SB, Moutquin JM, Farine D, et al. Neonatal survival rates in 860 singleton live births at 24 and 25 weeks gestational age. A Canadian multicentre study. BJOG. 2002;109:740-745.

2. Chawla D, Agarwal R, Deorari AK, Paul VK. Retinopathy of prematurity. Indian J Pediatr. 2008;75:73-76.

3. Zin A, Gole GA. Retinopathy of prematurity-incidence today. Clin Perinatol. 2013;40:185-200.

4. Smith LE. Pathogenesis of retinopathy of prematurity. Growth Horm IGF Res. 2004;14(Suppl A):S140-S144.

5. Hartnett M, Penn J. Mechanisms and management of retinopathy of prematurity. N Engl J Med. 2012;367:2515-2526.

6. Tatemoto K, Hosoya M, Habata Y, et al. Isolation and characterization of a novel endogenous peptide ligand for the human APJ receptor. Biochem Biophys Res Commun. 1998;251:471-476.

7. Dray C, Knauf C, Daviaud D, et al. Apelin stimulates glucose utilization in normal and obese insulin-resistant mice. Cell Metab. 2008;8: 437-445.

8. Kidoya H, Takakura N. Biology of the apelin-APJ axis in vascular formation. J Biochem. 2012;152:125-131.

9. Ballard JL, Khoury JC, Wedig K, Wang L, Eilers-Walsman BL, Lipp R. New Ballard score, expanded to include extremely premature infants. J Pediatr. 1991;119:417-423.

10. International Committee for the Classification of Retinopathy of Prematurity. The International Classification of Retinopathy of Prematurity revisited. Arch Ophthalmol. 2005;123:991-999.

11. Than A, Cheng Y, Foh LC, et al. Apelin inhibits adipogenesis and lipolysis through distinct molecular pathways. Mol Cell Endocrinol. 2012;362:227-241.

12. Fierson WM; American Academy of Pediatrics Section on Ophthalmology; American Academy of Ophthalmology; American Association for Pediatric Ophthalmology and Strabismus; American Association of Certified Orthoptists. Screening examination of premature infants for retinopathy of prematurity. Pediatrics. 2013;131:189-195.

Clinical Ophthalmology

\section{Publish your work in this journal}

Clinical Ophthalmology is an international, peer-reviewed journal covering all subspecialties within ophthalmology. Key topics include: Optometry; Visual science; Pharmacology and drug therapy in eye diseases; Basic Sciences; Primary and Secondary eye care; Patient Safety and Quality of Care Improvements. This journal is indexed on Submit your manuscript here: http://www.dovepress.com/clinical-ophthalmology-journal
13. Ye S, Hellstrom A, Smith LEH. Retinopathy of prematurity. In: Martin RJ, Fanaroff AA, editors. Fanaroff Martin's Neonatal-Perinatal Medicine. 10th ed. Philadelphia, PA: Elsevier Saunders; 2015:104.

14. Wang $Z$, Nakayama $T$. Inflammation, a link between obesity and cardiovascular disease. Mediators Inflamm. 2010;2010:535918.

15. Kasai A, Shintani N, Oda M, et al. Apelin is a novel angiogenic factor in retinal endothelial cells. Biochem Biophys Res Commun. 2004; 325:395-400.

16. Taquin AM, Syed R, Chadry TA. Retinopathy of prematurity: frequency and risk factors in a tertiary care hospital in Karachi, Pakistan. $J$ Pak Med Assoc. 2008;58:186-190.

17. Chen J, Connor KM, Aderman CM, Smith LE. Erythropoietin deficiency decreases vascular stability in mice. J Clin Invest. 2008;118: 526-533.

18. Chen J, Stahl A, Hellstrom A, Smith LE. Current update on retinopathy of prematurity: screening and treatment. Curr Opin Pediatr. 2011; 23:173-178.

19. Hadi AM, Hamdy IS. Correlation between risk factors during the neonatal period and appearance of retinopathy of prematurity in preterm infants in neonatal intensive care units in Alexandria, Egypt. Clin Ophthalmol. 2013;7:831-837.

20. Martínez-Cruz CF, Salgado-Valladares M, Poblano A, Trinidad-PérezMC. Risk factors associated with retinopathy of prematurity and visual alterations in infants with extremely low birth weight. Rev Invest Clin. 2012;64:136-143.

21. Malamitsi-Puchner A, Gourgiotis D, Boutsikou M, Baka S, Hassiakos D, Briana DD. Circulating apelin concentrations in mother/infant pairs at term, Acta Paediatrica. Acta Paediatr. 2007;96:1751-1754.

22. Cekmez F, Canpolat FE, Pirgon O, et al. Apelin, vaspin, visfatin and adiponectin in large for gestational age infants with insulin resistance. Cytokine. 2011;56:387-391.

23. Hajian-Tilaki K. Receiver Operating Characteristic (ROC) curve analysis for medical diagnostic test evaluation. Caspian J Intern Med. 2013;4(2):627-635.

24. Geiger K, Muendlein A, Stark N, et al. Hypoxia induces apelin expression in human adipocytes. Horm Metab Res. 2011;43:380-385.

25. Eyries M, Siegfried G, Ciumas M, et al. Hypoxia-induced apelin expression regulates endothelial cell proliferation and regenerative angiogenesis. Circ Res. 2008;103:432-440.

26. Kidoya H, Ueno M, Yamada Y, et al. Spatial and temporal role of the apelin/APJ system in the caliber size regulation of blood vessels during angiogenesis. EMBO J. 2008;27:522-534.

27. Lu Q, Jiang YR, Qian J, Tao Y. Apelin-13 regulates proliferation, migration and survival of retinal Müller cells under hypoxia. Diabetes Res Clin Pract. 2013;99:158-167.

28. Lim R, Barker G, Riley C, Lappas M. Apelin is decreased with human preterm and term labor and regulates prolabor mediators in human primary amnion cells. Reprod Sci. 2013;20:957-967.

29. Zhang Y, Jiang YR, Lu Q, Yin H, Tao Y. Apelin in epiretinal fibrovascular membranes of patients with retinopathy of prematurity and the changes after intravitreal bevacizumab. Retina. 2013;33:613-620.

30. Löfqvist C, Niklasson A, Engström E, et al. A pharmacokinetic and dosing study of intravenous insulin-like growth factor-I and IGF-binding protein-3 complex to preterm infants. Pediatr Res. 2009;65:574-579.

\section{Dovepress}

PubMed Central and CAS, and is the official journal of The Society of Clinical Ophthalmology (SCO). The manuscript management system is completely online and includes a very quick and fair peer-review system, which is all easy to use. Visit http://www.dovepress.com/ testimonials.php to read real quotes from published authors. 